\title{
The risk of uterine rupture after myomectomy: a systematic review of the literature and meta-analysis
}

\author{
J. Claeys • I. Hellendoorn • T. Hamerlynck • J. Bosteels • \\ S. Weyers
}

Received: 7 January 2014 / Accepted: 3 April 2014 /Published online: 10 May 2014

(C) Springer-Verlag Berlin Heidelberg 2014

\begin{abstract}
Fibroids may give rise to specific obstetrical complications such as pain due to degeneration, fetal malpresentation, or placenta previa. For all these reasons, surgical resection of the fibroid may be indicated before a pregnancy is pursued. The occurrence of a uterine rupture is a rare but severe complication of myomectomy. This study seeks to review the risk of uterine rupture during pregnancy and/or labor after laparoscopic myomectomy in comparison with laparotomic myomectomy. A systematic search of the literature through search strategies in MEDLINE (PubMed) and Embase (Embase.com) from January 1970 up to March 2013 was performed. We used the following MeSH terms and free text words: gynecologic surgical procedures, gynecologic surgery, leiomyoma, fibromyoma, fibroids, myoma, uterine tumors, and pregnancy complication. Our data show that the risk of uterine rupture during labor and delivery is low $(0.75 \%)$. Compared with traditional open myomectomy, the risk of uterine rupture during pregnancy is not significantly higher after a laparoscopic approach $(P=0.119)$. More elective cesarean sections are performed after laparoscopic myomectomy compared with the conventional open technique $(P=$ 0.001). Our conclusions are supported by statistical pooling of observational studies of generally low methodological quality. The risk of uterine rupture after myomectomy is low $(0.75 \%)$. The available evidence in the literature does no allow discouraging attempts for childbirth per viam naturalem after previous myomectomy, regardless of the technique used.
\end{abstract}

J. Claeys and I. Hellendoorn contributed equally to this manuscript.

J. Claeys $\cdot$ I. Hellendoorn $\cdot$ T. Hamerlynck $\cdot$ S. Weyers $(\bowtie)$ Department of Obstetrics and Gynecology, Ghent University Hospital, Ghent, Belgium

e-mail: steven.weyers@ugent.be

J. Bosteels

Department of Obstetrics and Gynecology, Imelda Hospital, Bonheiden, Belgium
Randomized studies are needed before definitive evidencebased recommendations can be given.

Keywords Myomectomy $\cdot$ Pregnancy $\cdot$ Uterine rupture

\section{Introduction}

During pregnancy, fibroids may cause pain due to degeneration, fetal malpresentation, or placenta previa. Therefore, surgical resection of the fibroid may be necessary before allowing women with fibroids to conceive. A laparotomic or laparoscopic approach will, in most cases, cause a scar in the myometrium, which may lead to weakening of the muscular wall and, by consequence, may increase the risk for the obstetric calamity of the sudden uterine rupture [1]. Nevertheless, it is at the present unclear whether an elective cesarean section may prevent all cases of uterine rupture during labor after previous scarring of the uterus [2].

For unselected pregnant women, the prevalence of uterine rupture is significantly lower in community-based studies (median 0.05, range 0.02-0.30\%) versus hospitalbased studies (median 0.31, range 0.01-2.90\%) [3]. Since most women suffering from severe pain after a previous myomectomy will be admitted in the emergency department of a hospital, the hospital-based studies are likely to reflect the true incidence of the problem under study. In women with a history of cesarean section, the prevalence rate is about $1 \%$ [3]. The frequency of uterine rupture is generally lower in developed countries versus undeveloped countries, as defined by the United Nations. The World Health Organization (WHO) recommends doing further clinical research to estimate the incidence of uterine rupture and to distinguish clearly between ruptures with or without previous surgery on the uterus. 
This study aimed to measure the likelihood of uterine rupture after myomectomy. We want to investigate if there are differences in the risk for this serious adverse event during pregnancy versus during the active labor stage. Moreover, we aimed to study if there are significant differences in the incidence of uterine rupture in women treated by laparoscopy versus classic open surgery.

\section{Materials and methods}

A systematic research of MEDLINE (PubMed) and Embase (Embase.com) for publications from January 1970 to March 2013 on the occurrence of uterine rupture after surgical myomectomy during pregnancy or labor was performed by using a combination of MeSH terms and free text words: gynecologic surgical procedures, gynecologic surgery, leiomyoma, fibromyoma, fibroids, myoma, uterine tumors, and pregnancy complication (Appendix 1). The results of the search are described in the attached PRISMA flowchart and checklist (Appendixes 2 and 3).

After removal of duplicates, 227 potentially useful publications were retained. The selection of potential studies to be included was done by reviewing the titles and abstracts by two authors (J.C. and J.B.) simultaneously and independently. Non-English articles were only used if an English abstract was available. If there was doubt, arbitration by the third review author (SW) was sought until consensus was reached. Finally, we included 56 articles for this meta-analysis [1, 4-58]. There was no selection based on the study methodology so that various types of articles were included, such as randomized controlled trials, case studies, case series, systematic and narrative reviews, comments, and letters to the editor.

The data extraction was performed by means of a standardized data extraction form (Appendix 4).

The data collected included the method of myomectomy, technique of suturing, location and size of the removed fibroids, time to pregnancy, setting of the study, and, for the published ruptures, the outcome of mother and child. In the absence of important information related to the type of surgery and the outcome of the mother or child, the authors were contacted in order to obtain this information.

If a single article stated that "no major obstetric complications happened," we assumed that no rupture had occurred. A statistical analysis was carried out on the data using Fisher's exact test in the statistical program SPSS.

\section{Results}

In the 56 included articles, a total number of 3,685 pregnancies after myomectomy were described, the majority of which $(2,017)$ following laparoscopic myomectomy, while 705 pregnancies occurred after laparotomic myomectomy and 484 pregnancies after other methods of myomectomy (hysteroscopic resection, myolysis, etc.). In 479 pregnancies, we failed to obtain any data on the method of myomectomy; these were excluded from further analysis.

Within these 3,685 pregnancies, 29 cases of uterine rupture were reported $(0.79 \%)$, one during labor and 28 prior to the onset of labor. There was a trend for an increased occurrence of uterine rupture following laparoscopic myomectomy (24 events/2,017 or $1.2 \%$ ) versus following laparotomic myomectomy (3 events/705 or $0.4 \%)$; the differences were not statistically significant $(P=0.119)$ (Fig. 1). There was one case of uterine rupture after hysteroscopic myomectomy, while in one case (the one rupture during labor), the mode of myomectomy was unknown [35]. The 28 ruptures during pregnancy occurred between 17 and 40 weeks of gestation, with $80 \%$ of the ruptures occurring between 28 and 36 weeks.

The number of planned vaginal deliveries and primary cesarean sections in the laparoscopic group was 401 and 544, respectively, as compared to 124 and 101 cases, respectively, in the open surgery group. The likelihood of a primary cesarean section was significantly increased following a laparoscopic versus a classic open myomectomy $(P=0.001)$.

Of the 401 women who attempted vaginal birth after laparoscopy, a large majority (373 women or $93 \%$ ) eventually experienced a successful vaginal delivery, while only 28 (7\%) women were delivered by secondary cesarean section. In the group of 124 women attempting vaginal delivery after myomectomy by an open approach, 109 (88\%) delivered vaginally compared to 15 (12\%) who needed to be delivered by secondary cesarean section. There were no significant differences for the risk of secondary cesarean section between women treated by laparoscopic versus classic open myomectomy $(P=0.090)$.

Just over $50 \%$ of the removed fibroids leading to a rupture of the uterine wall in a subsequent pregnancy were localized in the intramural part of the womb (13/24 or $54 \%$ ). The median size of the fibroid was $5 \mathrm{~cm}$. We found no clear correlation between the risk for a uterine rupture and location of the fibroid and suturing technique or whether the operation was done in a university or a non-university hospital. 


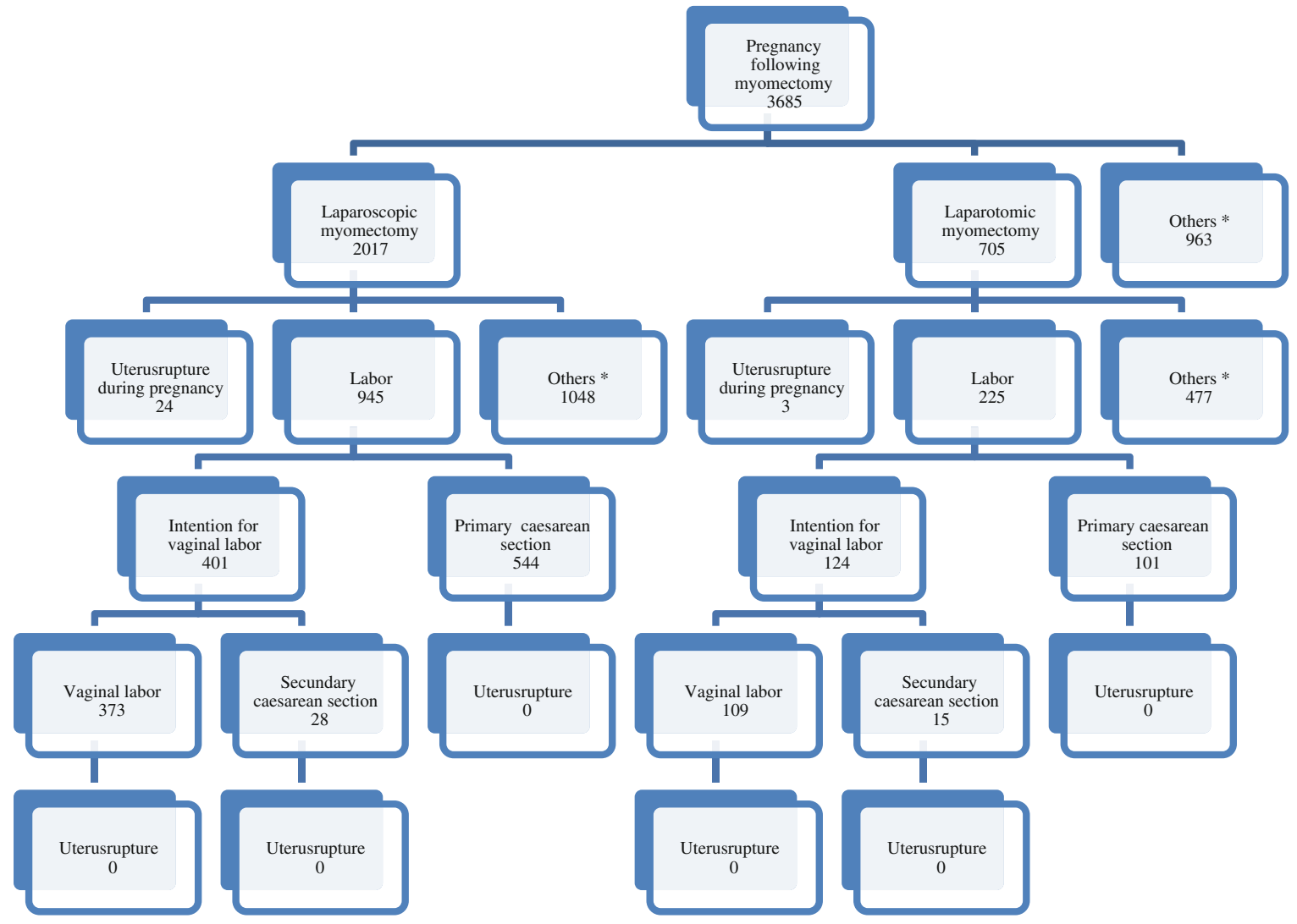

*Others: missing data, lost to follow-up, miscarriage, abortion, ectopic pregnancy

Fig. 1 Summary of pregnancies following myomectomy

When information on maternal and fetal outcome after rupture was unknown, we tried to contact the author. By doing this, we were able to obtain additional information in $75 \%$ of the contacted cases (three out of four). No difference was found in outcome of mother and child in relation to the setting (university versus non-university hospital). There were eight (33\%) neonatal deaths following a uterine rupture (five in the laparoscopic and three in the open surgery group). Our search failed to retrieve any report on maternal deaths following uterine rupture. This finding illustrates the high risk of publication bias associated with adverse events in the medical literature.

\section{Discussion}

A uterine rupture is very exceptional in developed countries and more frequent in developing countries due to prolonged labor caused by fetomaternal disproportion or second- stage disorders [2]. In developed countries, uterine rupture is almost exclusively observed following a previous cesarean section or previous surgery on the uterus, including myomectomy [59].

Our present systematic review identified pregnancies following myomectomy reported in the medical literature of the past four decades. We aimed to measure the incidence of uterine rupture after myomectomy in women wishing to conceive.

The prevalence of uterine rupture following myomectomy-all types of surgery- $(0.79 \%)$ is comparable with that after cesarean section. Based on the available evidence, there is no significant difference between the incidences of a rupture during pregnancy following a laparoscopic $(1.2 \%)$ versus an open myomectomy $(0.4 \%)$.

We observed a higher primary cesarean section rate after laparoscopic than after open myomectomy $(P=$ $0.001)$. This observation may be partially explained by 
confounding: between 1970 and 2013, there has been an overall increase in the cesarean section rates leading to a higher primary $\mathrm{C}$-section rate in the last two decades (the "era of laparoscopy") compared to the era of open surgery. Indeed, in the last two decades, the laparoscopic approach has become the preferred technique, with laparoscopic suturing requiring more than average technical expertise. The higher primary cesarean section rate in this group may similarly reflect the surgeon's anxiety that a laparoscopic myomectomy beholds a higher risk of rupture during subsequent pregnancy and labor compared to the open technique.

Furthermore, it is striking to observe that a uterine rupture in a woman following a myomectomy almost exclusively occurs during pregnancy and very exceptionally during active labor, as opposed to following a prior cesarean section. This can be explained to differences in the site of the incision with the majority of myomectomies being done in the corporeal part of the womb as opposed to the lower uterine segment in the case of cesarean delivery.

There is no significant increase in the risk for secondary cesarean section after laparoscopic compared with open myomectomy $(P=0.090)$. Attempts at vaginal birth seem equally highly successful following a laparoscopic or an open myomectomy (about $90 \%$ ). Moreover, none of the cases of secondary cesarean section was reportedly done for an impending uterine rupture. This finding should be interpreted with great caution, given that in the majority of published reports, no fully described reason for the secondary cesarean section was mentioned.

Furthermore, the occurrence of uterine rupture during labor was analyzed. There was one case of rupture during labor. Unfortunately, there were no data available whether this happened after laparotomic or open myomectomy. An attempt to obtain information from the primary study authors was not successful. It is important to note that this rupture during labor occurred under high-dose oxytocin administration, which, according to the author, could also have caused a rupture in an intact uterus [35].

It is clear that the location and size of the fibroids might affect the likelihood of uterine rupture following previous myomectomy. The limited number of events is too small to present definitive evidence on this subject. The same goes for the study of the relationship between the used suturing technique and the risk of uterine rupture. Also in the $\mathrm{C}$-section literature, there is conflicting evidence about a possible increased risk of uterine rupture after closure of the wound in one layer, while a large multicenter case-control study demonstrated that a single-layer closure, as compared to a twolayer closure, might be associated with an increased risk of rupture [odds ratio (OR) 2.69, $95 \%$ confidence interval (CI) 1.37-5.28]; a recent meta-analysis by Roberge et al. showed that only a locked single-layer closure leads to more ruptures (OR 4.96, $95 \%$ CI 2.58, 9.52) $[60,61]$. Additional studies in the future may provide more information.

Finally, most ruptures seem to occur in the mid-third trimester of pregnancy. Further research is needed to determine whether an adapted policy is needed in the third trimester of pregnancy in women who have undergone myomectomy.

The strength of this systematic review is that it is the first systematic literature review that was done to measure the incidence of uterine rupture following myomectomy based on the methodology of doing a systematic review of observational studies. Based on our findings, the risk of a uterine rupture following a myomectomy regardless of the technique used seems very rare (less than $1 \%$ of the ongoing pregnancies). This estimation of the incidence might be used for counseling women wishing to conceive after a myomectomy, but it should be stressed that given the nature of our present research (systematic review (SR) and meta-analysis of observational studies) this should be done with utmost caution. It is clear that randomized studies are needed to study the effectiveness of laparoscopic myomectomy for the adverse outcome of uterine rupture before conclusive evidence can be used to present evidence-based recommendations for daily clinical practice.

Our research has several important limitations. First of all, we restricted our search to publications with an English abstract, which implies a high risk for selection bias. Secondly, the classically described systematic underreporting of iatrogenic complications is inevitably a potential source of publication bias. The observation that only 29 cases of uterine rupture during pregnancy after myomectomy were published and there were no maternal deaths is almost certainly a major 
underestimation of the true unknown incidence of this potentially life-threatening event. Thirdly, the risk of rupture after laparoscopic myomectomy during labor is possibly underestimated since obstetricians seem to be more apt to do a primary cesarean section for fear of medical litigation after laparoscopic myomectomy. This leads to a high risk of performance bias. In addition, many studies lacked detailed information on complications during pregnancy or labor. When "no major obstetric complications" were noted, it was assumed that no uterine rupture had occurred. This assumption might be a cause of reporting bias. Finally, the present research is based on observational studies only; this inevitably causes a high risk of bias. By consequence, our present calculation of the incidence of uterine rupture following myomectomy, although very clinically relevant and usable for counseling in daily practice, is, at the best, an estimation. The evidence presented in the present SR should therefore be graded as very low. The research question posed in this research is highly relevant for clinical practice. Randomized studies on this topic are eagerly awaited by the obstetrical community. These should not be considered as unethical, given the equipoise for the society, the pregnant women, and their treating physicians. It is clear that a large pragmatic multicenter randomized study could answer this present uncertainty.

Acknowledgments We would like to thank Jens De Groot, university librarian of the University of Leuven, for helping with the search strategy in this study and Prof. Georges Van Maele, professor in biostatistics of the University of Ghent, for his contribution to the statistical analysis.

Funding No external funding was sought for this study.

Conflict of interest J.C., I.H., T.H., J.B., and S.W. declare that they have no conflict of interest.

\section{Appendix 1}

Search strategy for MEDLINE

((“Gynecologic surgical procedures"[Mesh:NoExp] OR ((Gynecologic[tiab] OR Gynecological[tiab]) AND (Surgical[tiab] OR Surgery[tiab] OR Surgeries[tiab]))) AND
("Leiomyoma"[Mesh] OR Leiomyoma[tiab] OR Leiomyomas[tiab] OR Fibromyoma[tiab] OR Fibromyomas[tiab] OR Fibroid[tiab] OR Fibroids[tiab] OR ((Fibroid[tiab] OR Fibroids[tiab] OR fibromas[tiab] OR Myoma[tiab] OR Myomas[tiab]) AND (uterine[tiab] OR uterus[tiab] OR tumor[tiab] OR tumors[tiab])))

AND

("Pregnancy complications"[Mesh] OR ((Pregnancy[tiab] OR Pregnancies[tiab]) AND (Complications OR Complication)))

Search strategy for Embase

1. Leiomyoma/exp (12048)

2. Leiomyoma:ab,ti AND [embase]/lim (4821)

3. Leiomyomas:ab,ti AND [embase]/lim (2876)

4. Fibromyoma:ab,ti AND [embase]/lim (126)

5. Fibromyomas:ab,ti OR fibroid:ab,ti OR fibroids:ab,ti AND [embase]/lim (3310)

6. (Fibroid OR fibroids OR fibromas OR myoma OR myomas) NEAR/1 (uterine OR uterus OR tumor OR tumors) AND [embase]/lim (7611)

7. No. 1 OR no. 2 OR no. 3 OR no. 4 OR no. 5 OR no. 6 (20910)

8. "Gynecologic surgery"/de (8320)

9. (Gynecologic OR gynecological) NEAR/1 (surgical OR surgery OR surgeries) AND [embase]/lim (85423)

10. No. 8 OR no. 9 (86669)

11. "Pregnancy complication"/exp (91673)

12. ((Pregnancy OR pregnancies) NEAR/1 (complications OR complication)):ab,ti AND [embase]/lim (2256)

13. No. 11 OR no. 12

14. No. 7 AND no. 10 AND no. 13

15. Leiomyoma/exp OR (leiomyoma:ab,ti AND [embase]/ lim) OR (leiomyomas:ab,ti AND [embase]/lim) OR (fibromyoma:ab,ti AND [embase]/lim) OR (fibromyomas:ab,ti OR fibroid:ab,ti OR fibroids:ab,ti AND [embase]/lim) OR ((fibroid OR fibroids OR fibromas OR myoma OR myomas) NEAR/1 (uterine OR uterus OR tumor OR tumors) AND [embase]/lim) AND (gynecologic surgery/de OR ((gynecologic OR gynecological) NEAR/1 (surgical OR surgery OR surgeries) AND [embase]/lim)) AND ((pregnancy OR pregnancies) NEAR/1 (complications OR complication)):ab,ti AND [embase]/lim 


\section{Appendix 2}

\section{PRISMA 2009 Flow Diagram}

Systematic search of the literature on MEDLINE (PubMed) and EMBASE (Embase.com)

$(\mathrm{n}=234)$

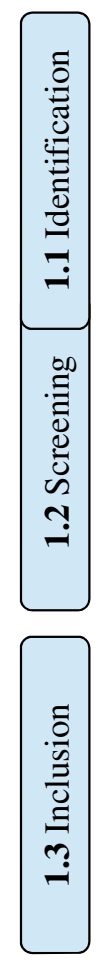

Articles found on Medline $(\mathrm{n}=113)$

Articles found on Embase $(\mathrm{n}=121)$

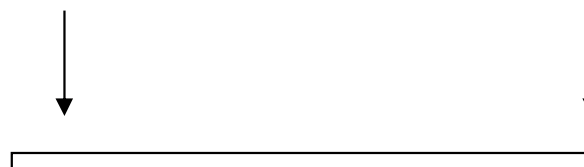

Possibly useful articles after removal of duplicates

$(\mathrm{n}=227)$

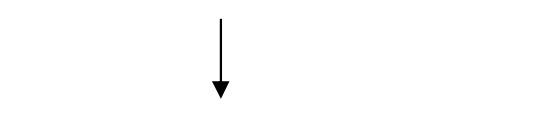

Possibly useful articles after screening of title and abstract

$(\mathrm{n}=60)$
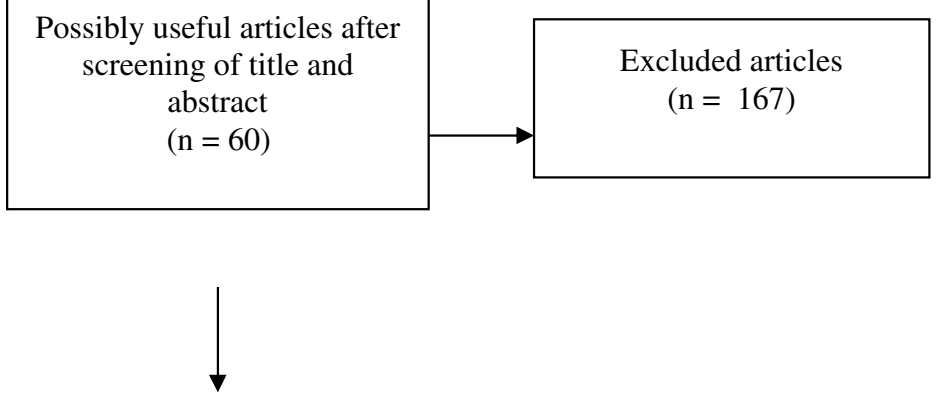

Articles retained after detailed $(\mathrm{n}=56)$

Excluded articles $(n=4)$ 


\section{Appendix 3}

\section{PRISMA 2009 Checklist}

\begin{tabular}{|c|c|c|c|}
\hline Section/topic & $\#$ & Checklist item & $\begin{array}{l}\text { Reported } \\
\text { on page \# }\end{array}$ \\
\hline \multicolumn{4}{|l|}{ TITLE } \\
\hline Title & 1 & Identify the report as a systematic review, meta-analysis, or both. & 1 \\
\hline \multicolumn{4}{|l|}{ ABSTRACT } \\
\hline Structured summary & 2 & $\begin{array}{l}\text { Provide a structured summary including, as applicable: background; objectives; data sources; study eligibility criteria, participants, } \\
\text { and interventions; study appraisal and synthesis methods; results; limitations; conclusions and implications of key findings; } \\
\text { systematic review registration number. }\end{array}$ & $2-3$ \\
\hline \multicolumn{4}{|l|}{ INTRODUCTION } \\
\hline Rationale & 3 & Describe the rationale for the review in the context of what is already known. & 4 \\
\hline Objectives & 4 & $\begin{array}{l}\text { Provide an explicit statement of questions being addressed with reference to participants, interventions, comparisons, outcomes, and } \\
\text { study design (PICOS). }\end{array}$ & 4 \\
\hline \multicolumn{4}{|l|}{ METHODS } \\
\hline Protocol and registration & 5 & $\begin{array}{l}\text { Indicate if a review protocol exists, if and where it can be accessed (e.g., Web address), and, if available, provide registration } \\
\text { information including registration number. }\end{array}$ & $4-5$ \\
\hline \multirow[t]{2}{*}{ Eligibility criteria } & 6 & Specify study characteristics (e.g., PICOS, length of follow-up) and report characteristics (e.g., years considered, language, & $4-5,27$ \\
\hline & & publication status) used as criteria for eligibility, giving rationale. & \\
\hline Information sources & 7 & $\begin{array}{l}\text { Describe all information sources (e.g., databases with dates of coverage, contact with study authors to identify additional studies) in } \\
\text { the search and date last searched. }\end{array}$ & 5 \\
\hline Search & 8 & Present full electronic search strategy for at least one database, including any limits used, such that it could be repeated. & $5,20-21$ \\
\hline Study selection & 9 & $\begin{array}{l}\text { State the process for selecting studies (i.e., screening, eligibility, included in systematic review, and, if applicable, included in the } \\
\text { meta-analysis). }\end{array}$ & 5,27 \\
\hline Data collection process & 10 & $\begin{array}{l}\text { Describe method of data extraction from reports (e.g., piloted forms, independently, in duplicate) and any processes for obtaining } \\
\text { and confirming data from investigators. }\end{array}$ & 5,27 \\
\hline Data items & 11 & $\begin{array}{l}\text { List and define all variables for which data were sought (e.g., PICOS, funding sources) and any assumptions and simplifications } \\
\text { made. }\end{array}$ & $5,20-21$ \\
\hline Risk of bias in individual studies & 12 & $\begin{array}{l}\text { Describe methods used for assessing risk of bias of individual studies (including specification of whether this was done at the study } \\
\text { or outcome level), and how this information is to be used in any data synthesis. }\end{array}$ & $3,8-9$ \\
\hline Summary measures & 13 & State the principal summary measures (e.g., risk ratio, difference in means). & 5 \\
\hline Synthesis of results & 14 & $\begin{array}{l}\text { Describe the methods of handling data and combining results of studies, if done, including measures of consistency (e.g., } I^{2} \text { ) for each } \\
\text { meta-analysis. }\end{array}$ & $5-7$ \\
\hline Section/topic & \# & Checklist item & $\begin{array}{l}\text { Reported } \\
\text { on page \# }\end{array}$ \\
\hline Risk of bias across studies & 15 & $\begin{array}{l}\text { Specify any assessment of risk of bias that may affect the cumulative evidence (e.g., publication bias, selective reporting within } \\
\text { studies). }\end{array}$ & 3,9 \\
\hline
\end{tabular}




\begin{tabular}{|c|c|c|c|}
\hline Additional analyses & 16 & $\begin{array}{l}\text { Describe methods of additional analyses (e.g., sensitivity or subgroup analyses, meta-regression), if done, indicating which were } \\
\text { pre-specified. }\end{array}$ & N/A \\
\hline \multicolumn{4}{|l|}{ RESULTS } \\
\hline Study selection & 17 & $\begin{array}{l}\text { Give numbers of studies screened, assessed for eligibility, and included in the review, with reasons for exclusions at each stage, } \\
\text { ideally with a flow diagram. }\end{array}$ & 5,22 \\
\hline Study characteristics & 18 & $\begin{array}{l}\text { For each study, present characteristics for which data were extracted (e.g., study size, PICOS, follow-up period) and provide the } \\
\text { citations. }\end{array}$ & $5-7,11-19$ \\
\hline Risk of bias within studies & 19 & Present data on risk of bias of each study and, if available, any outcome level assessment (see item 12). & $3,8-9$ \\
\hline Results of individual studies & 20 & $\begin{array}{l}\text { For all outcomes considered (benefits or harms), present, for each study: (a) simple summary data for each intervention group (b) } \\
\text { effect estimates and confidence intervals, ideally with a forest plot. }\end{array}$ & $5-7,17-19$ \\
\hline Synthesis of results 21 & 21 & $\begin{array}{l}\text { Present the main results of the review. If meta-analyses are done, include for each, confidence intervals and measures of } \\
\text { consistency. }\end{array}$ & $5-7$ \\
\hline Risk of bias across studies & 22 & Present results of any assessment of risk of bias across studies (see Item 15). & 3,9 \\
\hline Additional analysis & 23 & Give results of additional analyses, if done (e.g., sensitivity or subgroup analyses, meta-regression [see Item 16]). & N/A \\
\hline \multicolumn{4}{|l|}{ DISCUSSION } \\
\hline Summary of evidence & 24 & $\begin{array}{l}\text { Summarize the main findings including the strength of evidence for each main outcome; consider their relevance to key groups } \\
\text { (e.g., healthcare providers, users, and policy makers). }\end{array}$ & $7-9$ \\
\hline Limitations & 25 & Discuss limitations at study and outcome level (e.g., risk of bias), and at review-level (e.g., incomplete retrieval of identified & $8-9$ \\
\hline & & research, reporting bias). & \\
\hline Conclusions & 26 & Provide a general interpretation of the results in the context of other evidence, and implications for future research. & 2,9 \\
\hline \multicolumn{4}{|l|}{ FUNDING } \\
\hline Funding & 27 & $\begin{array}{l}\text { Describe sources of funding for the systematic review and other support (e.g., supply of data); role of funders for the systematic } \\
\text { review. }\end{array}$ & $2-3,10$ \\
\hline
\end{tabular}

\section{Appendix 4}

\section{Data extraction form}

\section{Sources}

i. All sources available were used

2. Intervention

i. Inclusion of laparoscopic myomectomy

ii. Inclusion of laparotomic myomectomy

iii. Inclusion of hysteroscopic myomectomy

iv. Exclusion of electromyolysis

v. Exclusion of a uterine embolization

For each intervention

i. Suturing technique

ii. Number of pregnancies following the intervention

iii. Attempting vaginal birth of primary cesarean section

iv. When attempting vaginal birth: vaginal birth of secondary cesarean section

v. Reason for secondary cesarean section

\section{Outcome}

i. Uterine rupture during pregnancy

ii. Uterine rupture during labor

For each rupture

i. When during pregnancy: week of pregnancy
ii. Setting
iii. Size of removed fibroids
iv. Location of removed fibroids
v. Outcome of child
vi. Outcome of mother

\section{References}

1. Parker W, Einarsson J, Istre O, Duboisson J et al (2010) Risk factors for uterine rupture after laparoscopic myomectomy. J Minim Invasive Gynecol 17(5):551-554

2. Murphy D (2006) Uterine rupture. Obstet Gynecol 18:135-140 
3. Hoffmeyr G, Say L, Gulmezoglu A et al (2005) WHO systematic review of maternal mortality and morbidity; the prevalence of uterine rupture. BJOG 112:1221-1228

4. Pritts EA (2001) Fibroids and infertility: a systematic review of the evidence. Obstet Gynecol Surv 56:483-491

5. Adesiyun A, Ojabo A, Durosinlorun-Mohmmed A et al (2008) Fertility and obstetric outcome after caesarean myomectomy. J Obstet Gynaecol 28(7):710-712

6. Bajekal N, Li T et al (2009) Fibroids, infertility and pregnancy wastage. Hum Reprod Update 6(6):614-620

7. Bernard G, Darai E, Poncelet C, Benifla J, Madelenat P et al (2000) Fertility after hysteroscopic myomectomy: effect of intramural myomas associated. Eur J Obstet Gynecol Reprod Biol 88:85-90

8. Bonito M, Gulemi L, Basili R, Roselli D et al (2007) Myomectomy during first and second trimester of pregnancy. Clin Exp Obstet Gynecol 34(3):149-150

9. Campo S, Campo V, Gambadauro P et al (2003) Reproductive outcome before and after laparoscopic or abdominal myomectomy for subserous or intramural myomas. Eur J Obstet Gynecol Reprod Biol 110:215-219

10. Celik C, Acar A, Cicek N, Gezginc K, Akyurek C et al (2002) Can myomectomy be performed during pregnancy? Gynecol Obstet Investig 53:79-83

11. Connolly G, Doyle M, Barrett T, Byrne P, De Mello M, Harrison R et al (2000) Fertility after abdominal myomectomy. J Obstet Gynaecol 20(4):418-420

12. Damiani A, Melgrati L, Marziali M, Sesti F et al (2003) Gasless laparoscopic myomectomy. J Reprod Med 48(10):792-798

13. Davies A, Hart R, Magos A et al (1999) The excision of uterine fibroids by vaginal myomectomy: a prospective study. Fertil Steril 71(5):961-964

14. Febo G, Tessarolo M, Leo L, Arduino S, Wierdis T, Lanza L et al (1997) Surgical management of leiomyomata in pregnancy. Clin Exp Obstet Gynecol 24(2):76-78

15. Gavai M, Hupuzi P, Papp Z et al (2006) Abdominal myomectomy as the alternative to hysterectomy: analysis of 504 cases. Orv Hetil 147(21):971-978

16. Gerli S, Baiocchi G, Favilli A, Di Renzo G et al (2011) New treatment option for early spontaneous rupture of a postmyomectomy gravid uterus. Fertil Steril 96(2):97-98

17. Goldberg J, Pereira L, Berghella V, Diamond J, Daraï E, Seinera P, Seracchioli R et al (2004) Pregnancy outcomes after treatment for fibromyomata: uterine artery embolization versus laparoscopic myomectomy. Am J Obstet Gynecol 191:18-21

18. Grande N, Catalano G, Ferrari S, Marana R et al (2005) Spontaneous uterine rupture at 27 weeks of pregnancy after laparoscopic myomectomy. J Minim Invasive Gynecol 12:131

19. Guillaume A, Benjamin F, Spitzer M et al (1998) Myomectomy performed concurrently with tuboplasty. J Reprod Med 43(6):483486

20. Guillaume J, Benjamin F, Jean-Gilles M, Ajah M, Tabassi G, KenelPierre $\mathrm{C}$ et al (2000) Myomectomy and tuboplasty performed at the same time in cases of distal tubal obstruction with associated fibroids. J Reprod Med 45(6):461-464

21. Hagnère P, Denoual I, Souissi A, Deswarte S et al (2011) Rupture uterine spontanée après myomectomie. À propos d'un cas et revue de la littérature. J Gynécol Obstét Biol Reprod 40:162-165

22. Jedrzejczak P, Pawelczyk L, Grewling K, Pelesz M, Serdynska M et al (2004) The assessment of the fertilization ability and the course of pregnancy in women after laparoscopic myomectomy. Przegl Lek 61(2):65-69

23. Kelly B, Bright P, MacKenzie I et al (2008) Does the surgical approach used for myomectomy influence the morbidity in subsequent pregnancy? J Obstet Gynaecol 28(1):77-81
24. Kucera E, Dvorska M, Krepelka P, Herman H et al (2006) Pregnancy after laparoscopic myomectomy-long-term follow-up. Ceska Gynekol 71(5):389-393

25. Kumakiri J, Takeuchi H, Kitade M, Kikuchi I, Shimanuki H, Itoh S, Kinoshita K et al (2005) Pregnancy and delivery after laparoscopic myomectomy. J Minim Invasive Gynecol 12(3):241-246

26. Kumakiri J, Takeuchi H, Itoh S, Kitade M, Kikuchi I, Shimanuki H, Kumakiri Y, Kuroda K, Takeda S et al (2008) J Minim Invasive Gynecol 15(4):420-424

27. Leidi L, Brusati M, Vespa M et al (2007) A treacherous scar. Am J Obstet Gynecol 197(5):553

28. Li T, Mortimer R, Cooke I et al (1999) Myomectomy: a retrospective study to examine reproductive performance before and after surgery. Hum Reprod 14(7):1735-1740

29. Lolis D, Kalantaridou S, Makrydimas G, Sotiriadis A, Navrozoglou I, Zikopoulos K, Paraskevaidis E et al (2003) Successful myomectomy during pregnancy. Hum Reprod 18(8):1699-1702

30. Malzoni M, Sizzi O, Rossetti A, Imperato F et al (2006) Laparoscopic myomectomy: a report of 982 procedures. Surg Technol Int 15:123129

31. Malzoni M, Tinelli R, Cosentino F, Iuzzolino D, Surico D, Reich $H$ et al (2010) Laparoscopy versus minilaparotomy in women with symptomatic uterine myomas: short-term and fertility results. Fertil Steril 93(7):2368-2373

32. Mara M, Maskova J, Fucikova Z, Kuzel D, Beslan T, Sosna O et al (2008) Midterm clinical and first reproductive results of a randomized controlled trial comparing uterine fibroid embolization and myomectomy. Cardiovasc Intervent Radiol 31(1):73-85

33. Marchionni M, Fambrini M, Zambelli V, Scarselli G, Susini T et al (2004) Reproductive performance before and after abdominal myomectomy: a retrospective analysis. Fertil Steril 82(1):154-159

34. Morita M, Asakawa Y et al (2006) Reproductive outcome after laparoscopic myomectomy for intramural myomas in infertile women with or without associated infertility factors. Reprod Med Biol 5: 31-35

35. Nezhat C, Nezhat F, Roemisch M, Seidman D, Tazuke S, Nezhat C et al (1999) Pregnancy following laparoscopic myomectomy: preliminary results. Hum Reprod 14(5):1219-1221

36. Obed J, Omigbodun A et al (1996) Rupture of the uterus in patients with previous myomectomy and primary caesarean section scars: a comparison. J Obstet Gynaecol 16(1):16-21

37. Okoro O, Onwere $\mathrm{S}$ et al (2007) Myomectomy during pregnancy. Pak J Med Sci 23(5):771-773

38. Pajszczyk-Kieszkiewicz T, Kazimierak W, Lech W, LipeckaKidawska E, Sieroszewski P, Kowalska-Koprek U et al (2002) Leiomyomas in pregnancy. Ginekol Pol 73(4):291-296

39. Park W, Jeon Y, Lee J, Shin S et al (2006) Subserosal pregnancy in a previous myomectomy site: a variant of intramural pregnancy. $\mathrm{J}$ Minim Invasive Gynecol 13(3):242-244

40. Persin J, Hanousek L et al (2006) Results of conservative surgery of uterine fibroids - 5 years of follow-up. Ceska Gynekol 71(4):322-325

41. Ploszynski A, Gniadek R, Adamcio-Deptulska M, Mielnik J et al (1997) Myomectomy and long-term follow-up. Ginekol Pol 68(9): 423-426

42. Plotti G, Plotti F, Di Giovanni A, Battaglia F, Nagar G et al (2008) Feasibility and safety of vaginal myomectomy: a prospective pilot study. J Minim Invasive Gynecol 15(2):166-171

43. Ramarajan A, Achar S et al (2012) Successful pregnancy following extensive myomectomy in a case of uterine leiomyomatosis. Int J Gynecol Obstet 199:S459

44. Ribeiro S, Reich H, Rosenberg J, Guglielminetti E, Vidali A et al (1999) Laparoscopic myomectomy and pregnancy outcome in infertile patients. Fertil Steril 71(3):571-574

45. Rossetti A, Sizzi O, Chiarotti F, Florio G et al (2007) Developments in techniques for laparoscopic myomectomy. J Soc Laparoendosc Surg 11(1):34-40 
46. Rovio P, Heinonen P et al (2006) Transvaginal myomectomy with screw traction by colpotomy. Arch Gynecol Obstet 273(4):211-215

47. Salfelder A, Lueken R, Gallinat A, Möller C, Busche D, Nugent W et al (1999) Laparoscopic myomectomy and pregnancy-results. Geburtshilfe Frauenheilkd 59(2):57-61

48. Sentilhes L, Sergent F, Berthier A, Catala L, Descamps P, Marpeau L et al (2006) Uterine rupture following operative hysteroscopy. Gynécol Obstét Fertil 34:1064-1070

49. Seracchioli R, Manuzzi L, Vianello F, Gualerzi B, Savelli L, Paradisi $\mathrm{R}$, Venturoli S et al (2006) Obstetric and delivery outcome of pregnancies achieved after laparoscopic myomectomy. Fertil Steril 86(1): 159-165

50. Sinclair D, Gaither K, Mason T et al (2005) Fertility outcomes following myomectomy in an urban hospital setting. J Natl Med Assoc 97(10):1346-1348

51. Sizzi O, Rossetti A, Malzoni M, Minelli L, La Grotta F, Soranna L, Panunzi S, Spagnolo R, Imperato F, Landi S, Fiaccamento A, Stola E et al (2007) Italian multicenter study on complications of laparoscopic myomectomy. J Minim Invasive Surg 14(4):453-462

52. Skrablin S, Banovic V, Kuvacic I et al (2005) Letters to the editorbrief communication. Successful pregnancy after spontaneous rupture of scarred uterus following fundal myomectomy. Eur J Obstet Gynaecol Reprod Biol 121(2):251-253

53. Soriano D, Dessolle L, Poncelet C, Benifla J, Madelenat P, Daraï E et al (2003) Pregnancy outcome after laparoscopic and laparoconverted myomectomy. Eur J Obstet Gynecol Reprod Biol 108(2):194-198

54. Suwadinata F, Gruessner E, Owandho C, Tinneberg H et al (2008) Pregnancy-preserving myomectomy: preliminary report on a new surgical technique. Eur J Contracept Reprod Health Care 13(3):323-326

55. Tinelli A, Hurst B, Hudelist G, Tin D, Stark M, Mettler L, Guido M, Malvasi A et al (2011) Laparoscopic myomectomy focusing on the myoma pseudocapsule: technical and outcome reports. Hum Reprod 27(2):427-435

56. Walid S, Heaton R et al (2010) Laparoscopic myomectomy: an intent-to-treat study. Arch Gynecol Obstet 281(4):645-649

57. Wong K, Tan J, Ang C, Ngu A et al (2010) Myomectomy scar ectopic pregnancy. Aust N Z J Obstet Gynaecol 50(1):93-98

58. Zollner U, Classen V, Steck T, Dietl J et al (2001) Fertility and pregnancy outcome after myomectomy. Geburtshilfe Frauenheilkd 61(4):213-219

59. Zwart J, Richters J, Öry F, De Vries J, Bloemenkamp K, Van Roosmalen J et al (2009) Uterine rupture in the Netherlands: a nationwide population-based cohort study. Int J Obstet Gynaecol 116:1069-1080

60. Bujold E, Goyet M, Marcoux S et al (2010) The role of uterine closure in the risk of uterine rupture. Obstet Gynecol 116:43-50

61. Roberge S, Chaillet N, Boutin A et al (2011) Single- versus doublelayer closure of the hysterotomy incision during cesarean delivery and the risk of uterine rupture. Int J Gynecol Obstet 115:5-10 